2. To: (Receiving Organization)

Distribution

5. Proj./Prog./Dept./Div.:

241-C-104/RPP/SST Interim Closure

8. Originator Remarks:

This document is being released into the supporting document system for retrievability purposes.

11. Receiver Remarks:

11A. Design Baseline Document? $\square$ Yes $\bigotimes$ No

For release

3. From: (Originating Organization)

SST Interim Closure Program

6. Design Authority/Design Agent/Cog. Engr.:

R. R. Thompson

\section{2}

$-\mathrm{C}-104$

12. Major Assm. Dwg. No.

$\mathrm{N} / \mathrm{A}$

13. Permit/Permit Application No.:

$\mathrm{N} / \mathrm{A}$

14. Required Response Date:

$9 / 22 / 00$

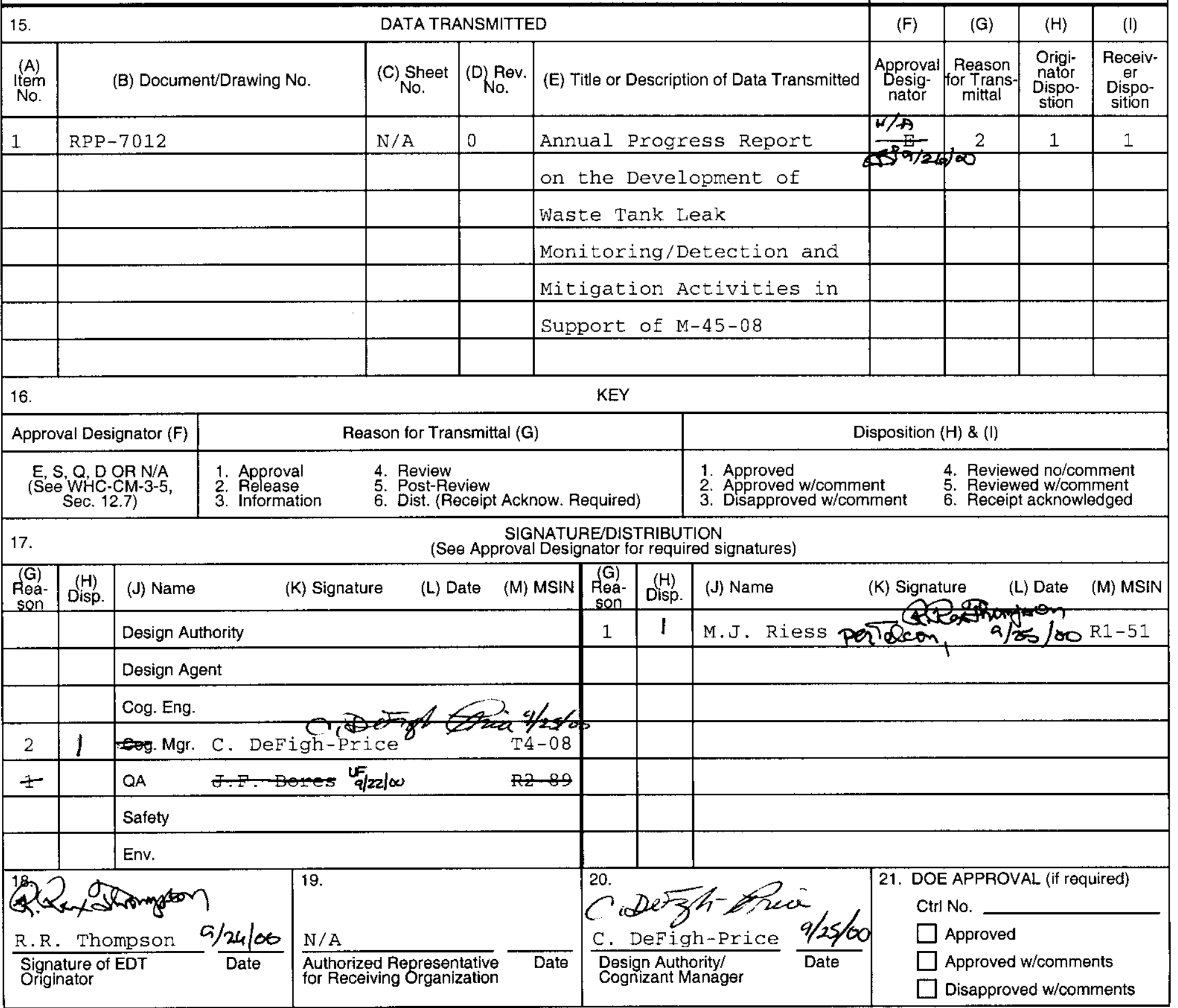




\section{DISTRIBUTION SHEET}

\begin{tabular}{|c|c|c|c|c|c|}
\hline $\begin{array}{l}\text { To } \\
\text { Distribution }\end{array}$ & \multicolumn{2}{|c|}{$\begin{array}{l}\text { From } \\
\text { SST Interim Closure Program }\end{array}$} & \multicolumn{3}{|c|}{ Page 1 of 1} \\
\hline \multirow{2}{*}{\multicolumn{3}{|c|}{ Project Title/Work Order }} & \multicolumn{3}{|c|}{ Date $9 / 22 / 00$} \\
\hline & & & \multicolumn{3}{|c|}{ EDT No. EDT-630487 } \\
\hline \multicolumn{3}{|c|}{$\begin{array}{l}\text { Annual Progress Report on the Development of Waste Tank Leak } \\
\text { Monitoring/Detection and Mitigation Activities in Support of M-45-08 }\end{array}$} & \multicolumn{3}{|c|}{ ECN No. N/A } \\
\hline Name & MSIN & $\begin{array}{c}\text { Text } \\
\text { With All } \\
\text { Attach. }\end{array}$ & Text Only & $\begin{array}{l}\text { Attach./ } \\
\text { Appendix } \\
\text { Only }\end{array}$ & $\begin{array}{c}\text { EDT/ECN } \\
\text { Only }\end{array}$ \\
\hline \multicolumn{6}{|l|}{ CH2M HILL HANFORD GROUP, INC. } \\
\hline J. J. Badden & $\mathrm{T} 4-08$ & $\mathrm{x}$ & & & \\
\hline J. F. Bores & $\mathrm{R} 2-89$ & $x$ & & & \\
\hline W. E. Bryan & $\mathrm{T} 4-07$ & $x$ & & & \\
\hline K. E. Carpenter & $\mathrm{T} 4-08$ & $x$ & & & \\
\hline D. W. Crass & $\mathrm{R} 3-47$ & $\mathrm{X}$ & & & \\
\hline C. DeFigh-Price & $\mathrm{T} 4-08$ & $\mathrm{x}$ & & & \\
\hline M. L. Deffenbaugh & $R 1-51$ & $\mathrm{x}$ & & & \\
\hline J. B. Hebdon & $\mathrm{R} 1-51$ & $\mathrm{x}$ & & & \\
\hline J.R. Janecke & $\mathrm{H} 6-16$ & $\mathrm{x}$ & & & \\
\hline W. J. Kennedy & $\mathrm{T} 4-07$ & $\mathrm{x}$ & & & \\
\hline D. B. Parkman & S5 -13 & $\mathrm{x}$ & & & \\
\hline R. E. Raymond & $\mathrm{T} 4-08$ & $\mathrm{x}$ & & & \\
\hline S. H. Rifaey & $\mathrm{T} 4-07$ & $\mathrm{x}$ & & & \\
\hline R. R. Thompson & $\mathrm{T} 4-08$ & $\mathrm{x}$ & & & \\
\hline W. T. Thompson & $57-90$ & $\mathrm{x}$ & & & \\
\hline R. C. Wilson & $T 4-08$ & $\mathrm{x}$ & & & \\
\hline \multirow[t]{2}{*}{ T.C.S.R.C. } & $\mathrm{R} 1-10$ & $\mathrm{x}$ & & & \\
\hline & & $\mathrm{x}$ & & & \\
\hline \multicolumn{6}{|l|}{ INFORMATICS } \\
\hline W. J. Stokes & $\mathrm{T} 4-08$ & $\mathrm{x}$ & & & \\
\hline \multicolumn{6}{|l|}{ LOCKHEED MARTIN SERVICES, INC. } \\
\hline Central Files & $\mathrm{B} 1-07$ & $\mathrm{x}$ & & & \\
\hline \multicolumn{6}{|l|}{ MACTEC } \\
\hline V. F. FitzPatrick & $\mathrm{R} 2-89$ & $\mathrm{x}$ & & & \\
\hline \multicolumn{6}{|l|}{ NUMATEC HANFORD COMPANY } \\
\hline C. J. Harden & R3-73 & $\mathrm{x}$ & & & \\
\hline \multicolumn{6}{|l|}{ OFFICE OF RIVER PROTECTION } \\
\hline DOE Reading Room & $\mathrm{H} 2-53$ & $\mathrm{x}$ & & & \\
\hline
\end{tabular}




\title{
Annual Progress Report on the Development of Waste Tank Leak Monitoring/Detection and Mitigation Activities in Support of M-45-08
}

\author{
c. DeFigh-Price \\ CH2M HILL Hanford Group, Inc. \\ Richland, WA 99352 \\ U.S. Department of Energy Contract DE-AC06-96RL13200
EDT/ECN: $\quad$ EDT-630487
UC: 2070
Org Code: 7LP0O
Charge Code: 106495
B\&R Code: EW 3120074
Total Pages: 78,23

Key Words: Tank 241-C-104, Tank C-104, TPA Milestone M-45-09E, waste tank leak detection, mitigation

Abstract: N/A

TRADEMARK DISCLAIMER. Reference herein to any specific commercial product, process, or service by trade name, trademark, manufacturer, or otherwise, does not necessarily constitute or imply its endorsement, recommendation, or favoring by the United States Government or any agency thereof or its contractors or subcontractors.

Printed in the United States of America. To obtain copies of this document, contact: Document Control Services, P.O. Box 950, Mailstop H6-08, Richland WA 99352, Phone (509) 372-2420; Fax (509) 376-4989.
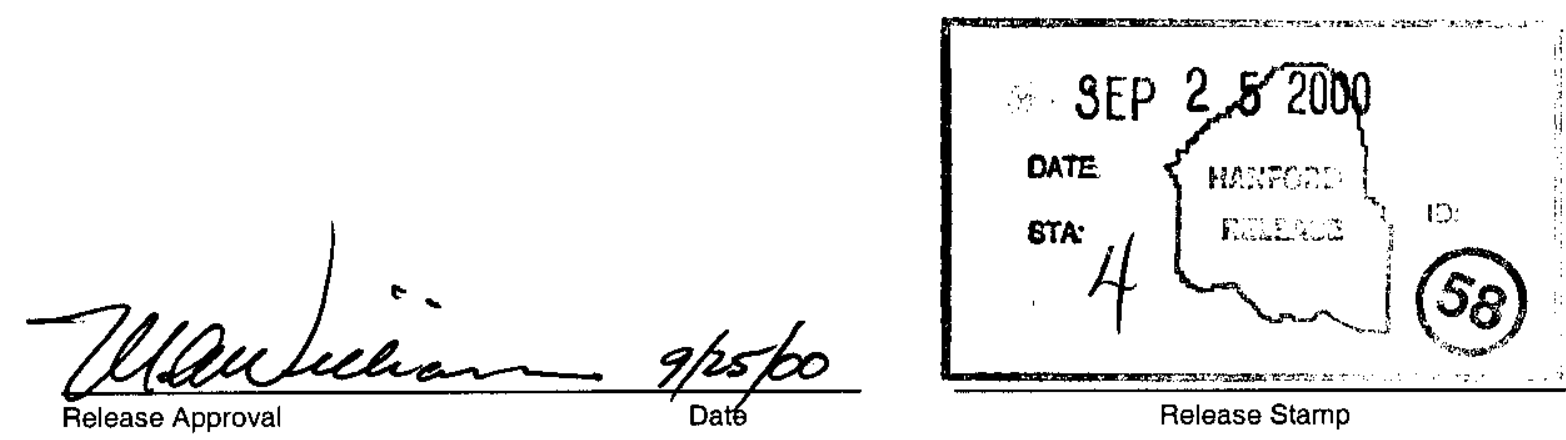

Approved For Public Release 
RPP-7012

Revision 0

\section{ANNUAL PROGRESS REPORT ON THE DEVELOPMENT OF WASTE TANK LEAK MONITORING/DETECTION AND MITIGATION ACTIVITIES IN SUPPORT OF M-45-08}

TPA Milestone M-45-09E

Fiscal Year 2000 Progress Report

Prepared by

CH2M HILL Hanford Group, Inc.

Prepared for

U.S. Department of Energy

Office of River Protection

September 22, 2000 
This page intentionally left blank. 


\section{TABLE OF CONTENTS}

1.0 INTRODUCTION

1.1 CURRENT LEAK DETECTION, MONITORING, AND MITIGATION

STRATEGY 1

1.2 SUMMARY OF FISCAL YEAR 2000 LEAK DETECTION, MONITORING, AND MITIGATION ACTIVITIES

2.0 TECHNOLOGIES 4

2.1 IN-TANK TECHNOLOGIES FOR LEAK DETECTION AND MONITORING

EX

2.2 EX-TANK TECHNOLOGIES FOR LEAK DETECTION AND MONITORING

2.3 TECHNOLOGIES FOR LEAK MITIGATION ……......................................... 6

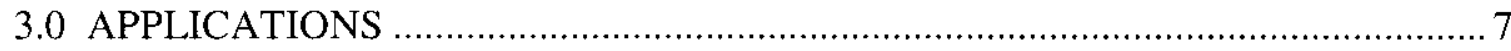

3.1 DESIGN CONCEPTS FOR IN-TANK LEAK DETECTION AND

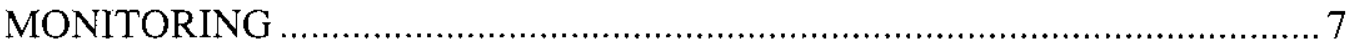

3.2 LEAK DETECTION, MONITORING, AND MITIGATION INTEGRATION WITH SLUICER AND CRAWLER PRELIMINARY' ENGINEERING

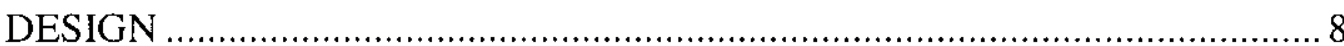

3.3 LEAK DETECTION, MONITORING, AND MITIGATION INTEGRATION WITH SALTCAKE DISSOLUTION PRELIMINARY ENGINEERING DESIGN

4.0 COST

5.0 SCHEDULE

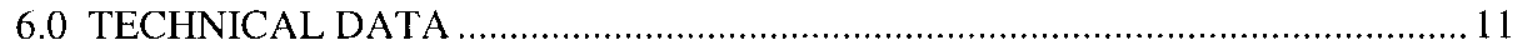

7.0 DEMONSTRATIONS RELATED TO LEAK DETECTION, MONITORING, AND

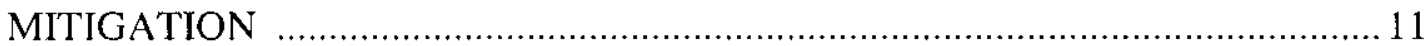

7.1 U.S. DEPARTMENT OF ENERGY DEMONSTRATIONS ……………........ 11

7.1.1 Hanford Tank 241-C-106 Retrieval ...................................................... 11

7.1.2 Oak Ridge Gunite and Associated Tanks (GAAT) .............................. 12

7.1.3 Savannah River Tank 19 Heel Removal Project ...................................... 13

7.2 PRIVATE INDUSTRY DEMONSTRATIONS ……….................................... 14

8.0 RECOMMENDATIONS FOR FURTHER TESTING ..........................................15

8.1 INTERSTITIAL LIQUID LEVEL MEASUREMENT …….............................. 15

8.2 DEPLOYMENT OF PRIMARY PUMP MINING STRATEGY ......................15

8.3 EX-TANK LEAK DETECTION AND MONITORING …………………........ 16

9.0 REFERENCES 


\section{LIST OF FIGURES}

Figure 5-1. Leak Detection, Monitoring, And Mitigation Activity Schedule 10

\section{LIST OF TERMS}

$\begin{array}{ll}\text { API } & \text { American Petroleum Institute } \\ \text { CHG } & \text { CH2M HILL Hanford Group, Inc. } \\ \text { DNAPL } & \text { dense non-aqueous phase liquids } \\ \text { DOE } & \text { U.S. Department of Energy } \\ \text { Ecology } & \text { Washington State Department of Ecology } \\ \text { EPA } & \text { U.S. Environmental Protection Agency } \\ \text { kgal } & \text { kilogallon } \\ \text { GAAT } & \text { Oak Ridge Gunite and Associated Tanks } \\ \text { LDMM } & \text { leak detection, monitoring, and mitigation } \\ \text { MEI-ILCR } & \text { maximally exposed individual-incremental lifetime cancer } \\ & \text { risk } \\ \text { NFESC } & \text { Naval Facilities Engineering Service Center } \\ \text { ORNL } & \text { Oak Ridge National Laboratory } \\ \text { SRS } & \text { Savannah River Site } \\ \text { SST } & \text { Single-shell tank } \\ \text { Tri-Party Agreement or TPA } & \text { Hanford Federal Facility Agreement and Consent Order }\end{array}$




\subsection{INTRODUCTION}

Milestone M-45-09E of the Hanford Federal Facility Agreement and Consent Order (Tri-Party Agreement or TPA) [TPA 1996] requires submittal of an annual progress report on the development of waste tank leak detection, monitoring, and mitigation (LDMM) activities associated with the retrieval of waste from single-shell tanks (SSTs). The text of the M-45-09 series of milestones reads:

"Submit annual progress reports on the development of waste tank leak monitoring/detection and mitigation activities in support of M-45-08. Reports will provide a description of work accomplished under M-45-08, technologies, applications, cost, schedule, and technical data. Reports will also evaluate demonstrations performed by DOE and private industry for applicability to SST retrieval and provide recommendations for further testing for use in retrieval operations."

This report details progress for fiscal year 2000, building on the current LDMM strategy and including discussion of technologies, applications, cost, schedule, and technical data. The report also includes discussion of demonstrations conducted and recommendations for additional testing. Tri-Party Agreement Milestones M-45-08A and M-45-08B required design and demonstration of LDMM systems for initial retrieval of SST waste. These specific milestones have recently been deleted as part of the M-45-00A change package. Future LDMM development work has been incorporated into specific technology demonstration milestones and SST waste retrieval milestones in the M-45-03 and M-45-05 milestone series.

\subsection{CURRENT LEAK DETECTION, MONITORING, AND MITIGATION STRATEGY}

The current strategy for LDMM activities is contained in the report, 1999 Leak Detection, Monitoring, and Mitigation Strategy Update (LMHC 1999b). This strategy, submitted to Washington State Department of Ecology (Ecology) in 1999, presented two major concepts for LDMM activities. The first concept was that design and development of LDMM activities should be completely integrated into the design and development of waste retrieval technologies. The second concept was that the methodology for risk-based Retrieval Performance Evaluation could be used to develop tank-by-tank SST closure source terms, which could in turn be used as a basis for release response criterion and ultimately development of retrieval release response actions. 
The SST closure source term that was described in LMHC (1999b) and will be used to establish tank-by-tank LDMM requirements is comprised of three components of risk allocation:

\author{
Past Leaks \\ Residual Waste \\ + Retrieval Release \\ $=$ SST Closure Source Term
}

The SST closure source term can be expressed in units of volume, concentration, or maximally exposed individual-incremental lifetime cancer risk (MEI-ILCR) ${ }^{1}$. Regardless of the units, a source term is only relevant when accompanied by reference to the point of compliance $^{2}$.

In the event a release is detected, a total release volume will be calculated based on the detected release rate and the estimated remaining retrieval time. This projected release volume will then be included in the closure source-term calculation, the potential MEI-ICLR will be calculated, and an appropriate operations response action will be initiated based on the potential MEI-ILCR at the point of compliance. For tanks in which the past leaks and residual waste exceed the established criteria for the MEI-ILCR at the point of compliance, tank-specific operational response actions will be developed using a similar methodology following a tank-specific closure evaluation.

\title{
1.2 SUMMARY OF FISCAL YEAR 2000 LEAK DETECTION, MONITORING, AND MITIGATION ACTIVITIES
}

In fiscal year 2000, LDMM activities became integrated with retrieval design concepts by including LDMM requirements in the preliminary design of retrieval systems. Three LDMM Design Concepts Evaluation Reports are scheduled to be issued in October 2000 to specifically address LDMM systems for sluicing-based, crawler-based, and saltcake dissolution-based retrieval systems (CHG 2000e, CHG 2000c, and CHG 2000d, respectively). These design concepts are developed based on the preferred alternatives identified in the 1998 Technology Trade Study Update (LMHC 1998a).

An important part of integrating LDMM activities into retrieval design concepts is delineating LDMM functions and allocating LDMM requirements to retrieval functions and requirements. LDMM functions applicable to all SST waste retrievals have previously been defined in the 1996 report, Functions and Requirements for Hanford Single-Shell Tank Leakage Detection and Monitoring (WHC 1996b). The SST retrieval-specific functions are:

\footnotetext{
${ }^{1}$ MEI-ILCR, a criteria used to represent potential threat to human health by a loss of waste from leaks during retrieval.

${ }^{2}$ Point of compliance is the geographical location where compliance is measured. For example, the point of compliance may be at the tank boundary, at the tank farm boundary, at the Site boundary or some other defined location.
} 
- TSD.2.2.6.1.5.1 Detect SST Waste Leakage During Retrieval-Pre-conceptual design definition: "Detect liquid waste releases from an SST during waste retrieval operations."

- TSD.2.2.6.1.5.2 Monitor SST Waste Leakage During Retrieval-Pre-conceptual design definition: "Quantify liquid waste release volumes from an SST, if a release is detected during waste retrieval operations."

- TSD 2.2.6.1.5.3 Mitigate SST Waste Leakage During SST Waste Retrieval-Preconceptual design definition: "Reduce the potential impact and respond appropriately to a liquid waste release, if a release is detected during waste retrieval operations."

These definitions of SST retrieval-specific LDMM functions reflect program changes and new information since the issue of the 1996 LDMM functions and requirements. These definitions are applicable to all wastes currently residing in Hanford SSTs. The function presented above for leak detection has not changed focus since 1996. However, the function of leak monitoring is now focused on quantifying the volume of the release, if one were to occur, rather than tracking the movement of the plume. Tracking and movement of a leak plume is now focused in the leak mitigation function to be addressed when a leak is detected.

Based on work conducted in fiscal year 2000, LDMM design considerations have been integrated into Preliminary Engineering Reports for waste retrieval from both tank 241-C-104 (CHG 2000f) and tank 241-S-103 (CHG 2000g). Both of these preliminary engineering reports are scheduled to be issued in September 2000. LDMM considerations have also been included in the Functions and Requirements Documents for waste retrieval systems associated with tanks 241-C-104 (CHG 2000a) and 241-S-103 (CHG 2000b). These specific documents will be updated to reflect the expanded scope identified in the recently negotiated M-45-00A milestone series and will be submitted to Ecology on the prescribed schedule. At that time the preliminary engineering reports for 241-S-103 will be modified to reflect changes resulting from the negotiated switch from 241-S-103 to 241-S-112 for the saltcake retrieval demonstration. 


\subsection{TECHNOLOGIES}

LDMM technologies have previously been evaluated in PNL (1994), PNL (1995), WHC (1996a), and LMHC (1998a). Development and integration of LDMM technologies with retrieval technologies is a key building block for success of the SST mission (LMHC 1998b). In fiscal year 2000, specific technologies were further developed for in-tank leak detection and monitoring, ex-tank leak detection and monitoring, and leak mitigation.

LDMM technology applications discussed in fiscal year 2000 include use of partitioning tracers, an emerging industrial technology for contamination plume characterization and site remediation, as an ex-tank leak detection and monitoring technology first addressed in LMHC (1999b). In addition, a new concept for deployment of primary retrieval pumps near the bottom of SSTs prior to starting retrieval, known as primary pump mining, was identified as a potential leak mitigation technology.

\subsection{IN-TANK TECHNOLOGIES FOR LEAK DETECTION AND MONITORING}

Based on studies conducted in fiscal year 2000 (CHG 2000c, CHG 2000d, and CHG 2000e), preferred in-tank technologies for leak detection and monitoring include:

- Mass balance

- Volumetric leak test

- Volumetric inventory balance leak detection.

Consistent with the recommendations in LMHC (1999b), volumetric and mass-based approaches have been selected as the preferred alternatives for leak detection and monitoring during initial SST waste retrieval demonstrations at the preliminary design level. These approaches have been proven in both the petroleum and chemical industries (API 1988, EPA 2000, and NFESC 1988) and are widely accepted by regulators (EPA 1988a, EPA 1988b, and EPA 1990). These approaches have been used in various forms at Hanford, most recently during Project W-320 for retrieval of waste from tank 241-C-106 (LMHC 1999a). These approaches are also attractive because their performance can be quantified in terms of probability of detection and probability of false alarm (LMHC 1998c). This performance will be a function of precision and accuracy of both free liquid surface monitoring and interstitial liquid monitoring. This decision will be revisited at set points (e.g., conceptual design and final design) during design to confirm it is still the selected method. 


\subsection{EX-TANK TECHNOLOGIES FOR LEAK DETECTION AND MONITORING}

Based on studies conducted in fiscal year 2000 (CHG 2000c, CHG 2000d, and CHG 2000e), alternative ex-tank technologies for leak detection and monitoring include:

- Drywell monitoring

- Post-retrieval soil sampling

- Partitioning tracers

- Electrical Resistance Tomography (electrical resistivity tomography).

Drywell monitoring and soil sampling are the current baseline technologies for external tank leak detection and monitoring. The drywells are constructed as closed wells so that soil and water do not infiltrate into the drywells. The drywells are installed adjacent to the tanks and extend below the bottom of the tanks. A probe is lowered up and down in a drywell to make radiation measurements at various depths. Leak detection is accomplished by periodic monitoring of the drywells. A significant change in radiation readings would be indicative of a potential release from a tank. Soil sampling is done as part of the on-going vadose zone and groundwater investigation program at Hanford. Radiation levels in soil samples can be used as another indicator of a potential release from a tank or tank farm.

Two emerging external tank technologies, Partitioning Tracers and Electrical Resistance Tomography, show promise for application to the Hanford SSTs. Partitioning Tracers utilize a series of injection and extraction wells to create a steady state forced gradient for injection of both conservative and partitioning tracers, which are analyzed at the extraction well. By analyzing the retardation of the partitioning tracer with respect to the conservative tracer, estimates can be made of the amount of moisture in the sweep path of the injection-extraction dipole and the extent of contamination can be inferred. Partitioning Interwell Tracer Tests have been used as an emerging industrial technology for contamination mapping and site remediation of Dense Non-Aqueous Phase Liquids (Gauglitz et al. 1999). Application of this technology for Hanford SST leak detection and monitoring would involve establishing a baseline moisture profile beneath the retrieval tank prior to initiation of retrieval. Changes in the moisture profile beneath the retrieval tank can be quantified and release volumes can be inferred.

Electrical Resistance Tomography relies on monitoring the electrical resistance between pairs of electrodes deployed around the retrieval tank. A baseline resistivity tomograph is established prior to initiation of retrieval. Increases in resistivity caused by a leak can be plotted. From these plots, estimates of release volume, release location, and plume tracking can be made.

Leak detection pits (sometimes referred to as leak detection caissons), which collect liquids that may leak from a tank into a lined pit that is monitored for liquid level and radioactivity have been considered in the past. Leak detection pits only exist in the 
241-AX tank farm, and three out of the four sets of leak detection laterals are currently categorized as nonfunctional (WHC-1995). In addition, leak monitoring laterals, which are typically three horizontal 4-inch pipe casings with 3-inch tubes used for gamma logging, exist under ten 241-SX tanks and six 241-A tanks. However, all sixteen lateral systems are non-functional due to internal contamination or abandoned equipment (WHC-1995). They have been eliminated for future consideration for leak detection.

\subsection{TECHNOLOGIES FOR LEAK MITIGATION}

Based on studies conducted in fiscal year 2000 (CHG 2000c, CHG 2000d, and CHG 2000e), preferred technologies for leak mitigation include:

- Auxiliary pump

- Primary pump mining

- Inherent liquid minimization.

All three of these mitigation technologies either limit the amount of free (drainable) liquids allowed to accumulate in an SST during waste retrieval or provide a means for removing free liquids, if a release is detected. Both the auxiliary pump and the primary pump mining strategy accomplish this removal by placing a pump capable of removing waste near the bottom of the tank. Primary pump mining is the current preferred leak mitigation strategy for preliminary engineering design for initial SST retrieval demonstrations (CHG 2000f, CHG 2000g, and LATA 1998). 


\subsection{APPLICATIONS}

In fiscal year 2000, based primarily on the technology studies mentioned above, applications consisted of developing design concepts for the in-tank leak detection and monitoring, and integrating LDMM design concepts with those of preferred retrieval technologies.

\subsection{DESIGN CONCEPTS FOR IN-TANK LEAK DETECTION AND MONITORING}

In-tank LDMM applications in fiscal year 2000 included development of design concepts for in-tank leak detection and monitoring. Design concepts were developed for two basic applications: (1) volumetric leak tests and (2) volumetric inventory balance leak detection. Both applications require internal tank monitoring of free surface and/or interstitial liquids. Both applications also require monitoring for sources of "noise" such as temperature and evaporation that can mask a leak or look like a leak and lead to missed detections or false alarms.

The approach to developing preliminary engineering design concepts for these applications leveraged well understood leak testing technologies from the petroleum industry to the Hanford SST application using existing SST instrumentation. Preliminary engineering performance envelopes for SSTs were developed which address the capability of existing SST instrumentation to meet the release criterion established by the retrieval release protection strategy (LMHC 1999b). The preliminary engineering performance envelopes were developed by extrapolating empirical petroleum tank data from similar size above-ground storage tanks (NFESC 1998 and EPA 2000) to empirical SST data (LMHC 1998c). The resulting performance envelopes in terms of detectable leak rates and test duration allowed preliminary engineering design of volumetric leak tests and volumetric inventory balance leak detection for both sludge and saltcake retrieval demonstrations. Actual performance of in-tank systems will likely be driven by the precision and accuracy of interstitial liquid monitoring during retrieval. Interstitial liquid monitoring during retrieval is included in technology development planning for fiscal year 2001 .

These performance estimates also allowed development of preliminary specifications and preliminary equipment lists for sluicing-based retrieval systems (CHG 2000e), crawler-based retrieval systems (CHG 2000c), and dissolution-based retrieval systems (CHG 2000d). 


\subsection{LEAK DETECTION, MONITORING, AND MITIGATION INTEGRATION WITH SLUICER AND CRAWLER PRELIMINARY ENGINEERING DESIGN}

In fiscal year 2000, preliminary engineering design concepts for sluicer-, crawler-, and combination sluicer/crawler-based retrieval systems were studied and included in the report, Preliminary Engineering Report for the 241-C-104 Retrieval System (CHG 2000f). These preliminary engineering design concepts are further developed with LDMM design concepts in reports for sluicing-based retrieval systems (CHG 2000e) and crawler-based retrieval systems (CHG 2000c). In these reports, design concepts, preliminary specifications, and preliminary equipment lists are identified for both volumetric leak testing (static) and volumetric inventory balance (static and dynamic) systems. These integrated design concepts are developed using the extrapolated performance envelope discussed in Section 3.1 to establish preliminary durations for volumetric leak tests and volumetric inventory balance leak detection.

Technology development needs associated with LDMM integration with sluicer- and crawler-based retrieval systems include selection of instrumentation and engineering development of methods to monitor interstitial liquid levels. Additional applied research and technology development is necessary so that external methods for contamination mapping can be applied to leak detection. In addition, deployment of the primary pump mining strategy is identified as an issue for resolution.

\subsection{LEAK DETECTION, MONITORING, AND MITIGATION INTEGRATION WITH SALTCAKE DISSOLUTION PRELIMINARY ENGINEERING DESIGN}

Similar to integration with sluicer and crawler preliminary engineering design, preliminary engineering design concepts for dissolution-based saltcake retrieval systems were studied in fiscal year 2000 and included in the report, Preliminary Engineering Report for the 241-S-103 Retrieval System (CHG 2000g). These preliminary engineering design concepts are further developed with the LDMM design concepts in a report for dissolution-based retrieval systems (CHG 2000e). In this report, design concepts, preliminary specifications, and preliminary equipment lists are identified for both volumetric leak testing (static) and volumetric inventory balance (dynamic) systems. Also similar to the sluicer and crawler integration, these integrated design concepts are developed using the extrapolated performance envelope discussed in Section 3.1 to establish preliminary durations for volumetric leak tests and volumetric inventory balance leak detection.

Permeability and hydraulic conductivity of saltcake waste is expected to be higher (i.e., interstitial liquids are expected to be more mobile) than sludge waste permeability and hydraulic conductivity. Because of this difference in waste characteristics, interstitial liquid levels are expected to be easier to monitor in saltcake waste than in sludge waste. Similar to integration with sluicing- and crawler-based retrieval systems discussed above, 
technology development needs associated with LDMM integration with dissolution-based retrieval systems include selection of instrumentation and engineering development of methods to monitor interstitial liquid levels and additional applied research and technology development is necessary so that external methods for contamination mapping can be applied to leak detection. Deployment of the primary pump is not an issue in tanks requiring saltcake dissolution because technology already exists for deploying saltwell screens in order to place the primary pump system.

\subsection{COST}

The near term funding profile for LDMM activities is planned at the levels below:

\begin{tabular}{cr}
$\begin{array}{c}\text { Fiscal } \\
\text { Year }\end{array}$ & $\begin{array}{c}\text { Budget } \\
\text { (Dollars K) }\end{array}$ \\
\hline 2000 & $\$ 189.0$ \\
2001 & $\$ 1,842.0$ \\
2002 & $\$ 3,125.0$ \\
2003 & $\$ 3,804.8$ \\
2004 & $\$ 4,291.8$ \\
2005 & $\$ 3,682.0$ \\
2006 & $\$ 1,096.4$ \\
TOTAL & $\$ 18,031.0$
\end{tabular}

This planned funding profile will support applied research and technology development, conceptual design, definitive design, construction/fabrication, installation, and demonstration of LDMM technologies through initial SST retrievals.

\subsection{SCHEDULE}

Figure 5-1 shows a level 1 schedule of activities for LDMM technology development to support both sludge and saltcake waste retrievals through 2006 . 


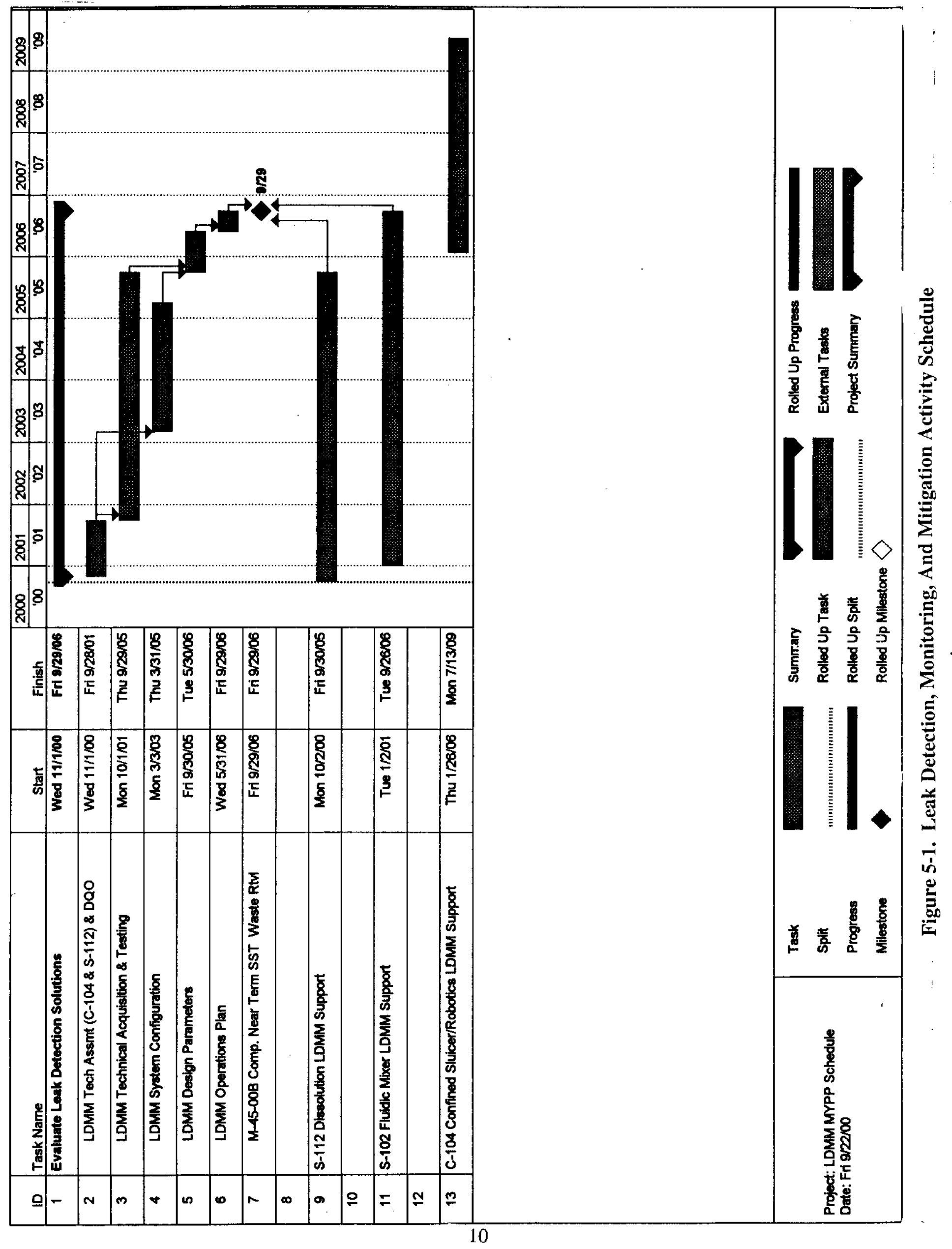




\subsection{TECHNICAL DATA}

There were no specific technical data taken for evaluation of LDMM technologies in fiscal year 2000 because there were no formal LDMM technology demonstrations. However, tank waste retrieval demonstrations were performed in fiscal year 2000 at Hanford, Oak Ridge, and Savannah River. These tank waste retrieval demonstrations and their LDMM activities are discussed below in Section 7.0.

\subsection{DEMONSTRATIONS RELATED TO LEAK DETECTION, MONITORING, AND MITIGATION}

Retrieval demonstrations that resulted in information pertinent to LDMM activities were conducted in fiscal year 2000 by both the U.S. Department of Energy (DOE) and private industry.

\subsection{U.S. DEPARTMENT OF ENERGY DEMONSTRATIONS}

As discussed in Section 6.0 above, there were no formal LDMM technology demonstrations performed in the DOE complex in fiscal year 2000. However, tank waste retrieval demonstrations that were performed at Hanford, Oak Ridge, and Savannah River along with their associated LDMM approaches are discussed in the following subsections.

\subsubsection{Hanford Tank 241-C-106 Retrieval}

The W-320 Project at Hanford retrieved $187 \mathrm{kgal}$ of sludge from tank 241-C-106 (COGEMA 2000). The waste retrieval was accomplished using a past-practice sluicing technology in 24-hour batches with 12 hours between batches to perform heat load/transfer calculations. The heat load calculations also provided data for mass balance leak detection.

The mass balance technique employed during Project W-320 (COGEMA 2000 and LMHC 1999a) used both retrieval tank and receiver tank level measurements from sensors such as ENRAFs ${ }^{3}$ and FICs $^{4}$. This sensor data was used in combination with in-tank video and with characterization data to convert volume data to mass data. The mass data was run through an algorithm to compare how much sluiced material (by

\footnotetext{
${ }^{3}$ ENRAF is a registered trademark of Enraf, Inc., of Houston, Texas. Some Hanford Site SSTs (and double-shell tanks [DSTs]) use the ENRAF 854 Servo Level Gauge for level indication.

${ }^{4}$ FIC is a registered trademark of Food Instrument Corporation (no longer in business). FIC level gauges were installed in SSTs and DSTs with liquid surfaces in the 1960s. Many FICs have been replaced with the more accurate and more reliable ENRAFs.
} 
weight) went into the retrieval tank and how much waste material (by weight) came out of the retrieval tank.

This technique requires liquid level interface measurements as well as shutdown of the retrieval operation to allow the level data to be acquired (this is true for most technologies using in-tank measurements). Because some tanks have solid surface layers, it is necessary to "punch through" the layer for direct measurement of a liquid interface. Alternatively, measurements in the liquid observation wells, where available, can be taken using indirect measurement of the interface through neutron probe or gamma activity to estimate the volume moved between retrieval operations. As in any measurement of fluctuating quantities, "baselines" of level and level trends need to be established and attributed to the causes for any observed change, before the data can be analyzed for "leaks," since the normal and routine changes in inferred mass need to be understood.

Flow rate-augmented mass balancing techniques have the potential to improve accuracy by measuring the rate at which liquids and slurries are transferred. Flow rate measurements were collected during the tank 241-C-106 retrieval operation, but the data has not been analyzed in terms of mass transfer. When this data is analyzed, the benefits and limitations of flow rate-augmented data will be more evident. In cases where no liquid interface is measurable, such as might be found in tanks containing stabilized sludges, this technique has limited value. The tank 241-C-106 retrieval operations did not use the mass balance method for leak detection; a heat load management method was used for that project.

\subsubsection{Oak Ridge Gunite and Associated Tanks (GAAT)}

The Oak Ridge Gunite and Associated Tanks (GAAT) project has successfully completed waste retrieval on eight gunite tanks at the Oak Ridge National Laboratory between 1996 and 2000. The tanks include two 50-kgal gunite tanks in the North Tank Farm and six 140-kgal tanks in the South Tank Farm. Waste retrieval was completed for the last two tanks (W-8 and W-9) in fiscal year 2000 .

The GAAT waste retrieval system consists of the Modified Light-Duty Utility Arm, Confined Sluicing End Effector, and the Houdini. The Houdini is a multifunctional remotely operated crawler. Tank W-9 contained heavy sludge from previous waste consolidation efforts. A heavy-waste retrieval system consisting of an airlift system and heavy-duty pumps was used along with the three other technologies to successfully mobilize and transfer the wastes from the tank.

Leak detection and monitoring for the GAAT project was provided via an external tank monitoring system combined with internal tank volumetric techniques. The gunite tanks were monitored for a large sudden release by using the on-line level measurements that were monitored around the clock at the Waste Operations Control Center. Volumetric precision leak testing was accomplished by analyzing 48-hour data sets of tank level readings that were taken at one-minute intervals. The precision testing was conducted 
prior to waste retrieval operations to establish baseline conditions. The external leak monitoring system and the Waste Operations Control Center monitoring were used during waste retrieval operations.

The external leak monitoring system utilized the drywells adjacent to each tank to monitor the conductivity of the groundwater that naturally flows around the tanks. A significant increase in conductivity would indicate a potential release from a tank. The system worked because the groundwater conductivity is approximately two orders of magnitude (100 times) less than the conductivity of the fluids in the tanks. Field-testing showed that leaks on the order of 0.5 gallons per minute could be detected using the external drywell monitoring method. The method was deployed and used during all GAAT waste retrieval operations. The external drywell monitoring leak detection system has allowed the GAAT project to use several of the inactive tanks (W-8 and W-9) in the South Tank Farm for the temporary storage of sluiced material and supernatant liquids. This use has, in turn, resulted in significant cost avoidance and reduction in schedule by eliminating the need to construct new above-ground tanks and facilitating an efficient transfer of wastes out of the tanks (ORNL 1998).

\subsubsection{Savannah River Tank 19 Heel Removal Project}

At the Savannah River Site (SRS), long-shaft mixer pumps are being used for initial waste retrieval from the underground double-shell tanks, in particular Tank 19. Waste mixing and removal using the slurry pumps has left approximately $40 \mathrm{kgal}$ of residual sludge as waste heel in Tank 19. In a joint effort between Westinghouse Savannah River Company and the Tanks Focus Area, the use of Flygt Mixer technology is being demonstrated as a means to remove the waste heel from Tank 19 and other SRS tanks.

Two years of scale up and verification testing of the Flygt Mixers were conducted at Pacific Northwest National Laboratory and the SRS TNX Test Facility. Following this effort, the third of three Flygt Mixers was installed in Tank 19 on August 2, 2000. The schedule calls for mixing to begin in September, with completion of waste retrieval in Tank 19 within approximately 1 month.

Leak detection in the SRS double-shell tanks is accomplished by monitoring the annular space between the inner and outer tanks with radiation monitors and electrical resistance leak detectors (SRS 1995). Nine tanks have leaked in the past, and tank liquids were detected in the annular space via radiation monitors and annulus photography (SRS 1995). The groundwater at the SRS typically ranges from ten to twenty feet below grade, and groundwater sampling is also used as part of the leak detection strategy. 


\subsection{PRIVATE INDUSTRY DEMONSTRATIONS}

There were no specific DOE observed private industry LDMM demonstrations in fiscal year 2000. The Strategic Environmental Research and Development Program (SERDP) sponsored an applied research project through Pacific Northwest National Laboratory. The applied research project was to perform non-intrusive characterization of dense nonaqueous phase liquids (DNAPLs) in the subsurface (Gauglitz et al. 1999, 2000). The results of the research indicate that short-lived radiotracers in partitioning interwell tests can detect fluid saturation in the subsurface. An adaptation of this approach has been proposed to quantify year baseline soil moisture changes in the vadose zone immediately surrounding an underground storage tank as a leak detection technique. Previous studies have shown that under the ideal conditions of equilibrium partitioning, gaseous water-soluble tracers can quantify the water content in the vadose zone through an extension of earlier developments in partitioning tracers for delineating DNAPL contamination in aquifers and the vadose zone (Deeds et al. 1999; Jin et al. 1995; and Whitley et al. 1999). 


\subsection{RECOMMENDATIONS FOR FURTHER TESTING}

Work in fiscal year 2000 identified several needs for design and development of LDMM technologies. None of the technology needs presented represent basic research. Rather, these technology needs represent (1) application-specific engineering development and testing to validate the design concepts developed in fiscal year 2000; and

(2) advancement of technologies that have been proven in field tests but have yet to be deployed in an operational environment.

\subsection{INTERSTITIAL LIQUID LEVEL MEASUREMENT}

Measurement of interstitial liquids is necessary to utilize the mass balance and volumetric in-tank technologies. The primary issue with deploying an interstitial liquid measurement technology is making accurate measurements in the material at the bottom of the tanks. This material can consist of multiple layers of partially or fully saturated sludge. Capillary action can draw liquids up into the pores of the unsaturated sludge, causing a moisture gradient to form; in this case, there is no clear demarcation of the liquid level. In addition, while measurement of a free supernatant layer is relatively straightforward, measurement of an interstitial liquid or moisture/saturation level is more difficult because direct level-sensing instruments may not be sufficient. As a result, inferential sensors must be employed. Further, since the sludges in question are also radioactive and highly conductive, many standard industrial bulk density and liquid content measuring methods become impractical in this application. The problem, therefore, becomes one of identifying sensors that are tractable, readily deployable, and affordable, and whose performance is consistent with the needs of leak detection and leak monitoring systems. Additional uncertainties include the number of sensors necessary, appropriate location(s), and which interstitial liquid level measurement technique to use.

These uncertainties can be managed by establishing an engineering development and technology testing program to establish performance requirements and capabilities for interstitial liquid level measurements. Once technical performance requirements have been established, an appropriate design concept can be further developed and tested for selection and incorporation into the LDMM system conceptual design. Because sufficiently low programmatic risk is associated with this issue, testing and engineering development can proceed in parallel with formal project definition.

\subsection{DEPLOYMENT OF PRIMARY PUMP MINING STRATEGY}

Primary pump mining is a preferred alternative for leak mitigation. This approach places a pump near the bottom of the tank during retrieval. Conceptually, it is straightforward to place a 60-horsepower retrieval slurry pump near the bottom of the retrieval tank for rapid removal of free (i.e., drainable) liquids in the event a leak is detected. However, the 
engineering details of deploying the slurry pump through 10 to 15 feet of sludge are not straightforward and have not been demonstrated in a SST. The shear strength of the sludge may be such that the pump will not simply sink into the sludge or such that the pump could seize if it were to sink into sludge that had not been mobilized by the sluicing jets. In addition, alternative leak mitigation approaches such as auxiliary pumps and inherent liquid minimization are not sufficiently developed to use as contingencies.

The baseline approach to sluicing the pump into the sludge and allowing it to sink must be tested on simulated wastes to validate the approach and proceed with conceptual design. In the event the baseline approach is found to be deficient, alternate design concepts must be evaluated and validated. Formal conceptual design of an integrated waste retrieval system and LDMM system should proceed in parallel.

\subsection{EX-TANK LEAK DETECTION AND MONITORING}

Many Hanford sludges and saltcakes are permeable, where liquid will flow from one location to another. The rate of flow from one location in the tank to another is controlled by sludge permeability. However, in a tank containing impermeable sludge, liquids do not flow horizontally or vertically except through macro channels in the waste matrix. Leak detection and leak monitoring for this scenerio may be best accomplished through external tank technologies.

The most viable external monitoring technologies appear to be Partitioning Tracers and Electrical Resistivity Tomography. Both of these emerging technologies have been used in industrial trials and applications for contamination mapping and site remediation.

What is needed is applied testing and evaluation to develop leak detection and monitoring protocols and methodologies from the existing contamination mapping protocols and methodologies. Once these protocols and methodologies have been developed and tested, a preliminary engineering evaluation of the performance of these systems for SST leak detection and monitoring can be performed. These studies can be conducted in parallel with formal conceptual designs. 


\subsection{REFERENCES}

API, 1988, A Leak Detection Performance Evaluation of Automatic Tank Gauging Systems and Product Line Leak Detectors at Retail Stations. Final Report for the American Petroleum Institute.

CHG, 2000a, Functions and Requirements for the Tank 241-C-104 Waste Retrieval System, RPP-6525, Rev. 0, CH2M HILL Hanford Group, Inc., Richland, Washington, 2000.

CHG, 2000b, Functions and Requirements for the Tank 241-S-103 Waste Retrieval System, RPP-6691, Rev. 0, CH2M HILL Hanford Group, Inc., Richland, Washington, 2000.

CHG, 2000c, Leak Detection, Monitoring, and Mitigation Design Concepts Evaluation Report-Crawler Based Retrieval Technologies, (Draft), RPP-6796, Rev. 0, CH2M HILL Hanford Group, Inc., Richland, Washington

CHG, 2000d, Leak Detection, Monitoring, and Mitigation Design Concepts Evaluation Report-Saltcake Dissolution Based Retrieval Technologies (Draft), RPP-6797, Rev. 0, CH2M HILL Hanford Group, Inc., Richland, Washington.

CHG, 2000e, Leak Detection, Monitoring, and Mitigation Design Concepts Evaluation

Report - Sluicing Based Retrieval Technologies (Draft), RPP-6795, Rev. 0, CH2M HILL Hanford Group, Inc., Richland, Washington.

CHG, 2000f, Preliminary Engineering Report for the 241-C-104 Retrieval System (Draft), RPP-6843, Rev. 0, Holmes and Narver for CH2M HILL Hanford Group, Inc., Richland, Washington.

CHG, 2000g, Preliminary Engineering Report for the 241-S-103 Retrieval System, RPP-6830, Rev. 0, Holmes and Narver for CH2M HILL Hanford Group, Inc., Richland, Washington.

COGEMA, 2000, Waste Retrieval Sluicing System and Project W-320, Tank C-106 Sluicing, Lessons Learned. RPP-5687, Rev. 0, COGEMA Engineering Corporation, Richland, Washington.

Deeds, N. E., D. C. McKinney, G. A. Pope, and G. A. Whitley, 1999, "Difluoromethane as a partitioning tracer to estimate vadose water saturations." JEnv Engr, in press. 
EPA, 1988a, Evaluation of Volumetric Leak Detection Methods for Underground Fuel Storage Tanks, Vol. I (EPA/600/ 2-88/068a) and Vol. II (EPA/600/2-88/068b). Risk Reduction Engineering Laboratory, U.S. Environmental Protection Agency, Edison, New Jersey.

EPA, 1988b, 40 CFR 280 - Technical Standards and Corrective Action Requirements for Owners and Operators of Underground Storage Tanks. Federal Register, 53: 185, U.S. Environmental Protection Agency, Washington, D.C..

EPA, 1990, Standard Procedures for Evaluating Leak Detection Methods: Volumetric Tank Tightness Testing Methods, EPA Report No. EPA/530/UST-90/004, U.S. Environmental Protection Agency, Washington, D.C..

EPA, 2000, List of Leak Detection Evaluations for Underground Storage Tank (UST) Systems. $7^{\text {th }}$ Edition, U.S. Environmental Protection Agency, Washington, D.C.

Gauglitz, P. A., G. A. Pope, B. Zemel, R. J. Cameron, R. W. Goles, B. M. Rapko, and J. M. Tingey, 1999, "DNAPL Characterization Using Short-Lived Radiotracers in Partitioning Interwell Tracer Tests", SERDP/ESTCP - Partners in Environmental Technology Symposium and Workshop, November 30 - December 2.

Gauglitz, P. A., G. A. Pope, B. Zemel, R. J. Cameron, R. W. Goles, and B. Rouse, 2000, "DNAPL Characterization Using Short-Lived Radiotracers in Partitioning Interwell Tracer Tests", Remediation of Chlorinated and Recalcitrant Compounds, $2^{\text {nd }}$ International Conference, Monterey, California, May 22-25.

Jin, M., M. Delshad, V. Dwarakanath, D. C. McKinney, G. A. Pope, K. Sepehrnoori, and C. E. Tilburg, 1995, "Partitioning Tracer Test for Detection, Estimation and Remediation Performance Assessment of Subsurface Nonaqueous Phase Liquids," Water Resources Res 31(5):1201-1211.

LATA, 1998, Draft Mining Strategy Plan, 10245-CD-012, Rev. A, Los Alamos Technical Associates, Inc., Richland, Washington.

LMHC, 1998a, Leak Detection, Monitoring, and Mitigation Technology Trade Study Update, HNF-SD-WM-ES-379, Rev. 1, Lockheed Martin Hanford Corporation, Richland, Washington.

LMHC, 1998b, Tank Waste Remediation System Mission Analysis Report, HNF-SD-WM-MAR-008, Rev. 3, Lockheed Martin Hanford Corporation, Richland, Washington.

LMHC, 1998c, Single-Shell Tank Sluicing History and Failure Frequency, HNF-3018, Rev. 0, Lockheed Martin Hanford Corporation, Richland, Washington. 